\title{
A Teaching Reform Design for Civil Engineering English Course
}

\author{
Yan Li \\ Department of Foreign Language, The Engineering \& technical college of Chengdu University of \\ Technology, Leshan, Sichuan, China \\ 295199077@qq.com
}

Keywords: civil engineering English, teaching reform, course design

\begin{abstract}
English for civil engineering in colleges is part of English for specific purpose (ESP) which rose in the 1960s, while its research in China is still in early stage and it aims mainly on economic English but seldom on civil engineering English in China. The paper is about to propose a teaching reform design for civil engineering English course based on the analysis of the course' current problems. The design mainly consist of four parts from the update of teaching materials and objective, the application of teaching methods, the cultivation of qualified teachers and the motivation of students.
\end{abstract}

\section{Introduction}

With the development of science and technology, it is admitted that the requirements for the civil engineering employees have been increasingly raised. As for the civil engineering graduates, they are not only required to translate all kinds of civil engineering materials, but also to be capable of solving all the problems in English when they participate in the procedures of the civil engineering projects, such as negotiation, designation, management, and after-service. Thus, the course requirements of civil engineering English should take it into consideration. But civil engineering English, as a major course for the civil engineering majors, is just a new established course and has been simply taken as an academic subject in China. As a consequence, there are many problems during the process of teaching. For example, this course is taught either by the teachers of elementary English courses, or by the teachers of civil engineering major course, who purely translate the specific knowledge into English. Then, it is necessary to explore how to master this course at present.

\section{Current Situation for Civil Engineering English Course}

Civil Engineering English course, compared with other elementary English courses, has its own unique features. The first is that civil engineering English is more accurate to illustrate the objectives with little rhetorical devices. Then there are a lot of sentences in passive voice with plenty of noun phrases and clauses. Besides, as a branch of English for Specific Purposes (ESP), civil engineering English contains a large amount of technical terms, which has narrow lexical sense. Due to the unique features of civil engineering English, it is very necessary to consider the teaching of this course. But there are a lot of problems. In this paper, the writer mainly discusses the following four problems on the basis of the analysis on others' studies.

Outdated Content.The content $\mathrm{f}$ the course, in a relative sense, is out of date. The same textbook is usually used to uniform the teaching materials in colleges without considering the subtle difference among sub-majors of civil engineering. Then, the content is too wide, which is difficult for the teachers to choose and master, or too narrow, which caused some of the advanced techniques, which have long been applied to practice, are not contained in the teaching materials.

Improper Teaching Objective and Methods.The objective of the course used to cultivate the reading ability of students in civil engineering. Then the teachers and students focused on vocabulary learning and translation of texts, unaware of other English abilities, such as listening, speaking, reading, writing and so on. Meanwhile, for the class, it was teacher-centered, in which the teacher tried to talk for the most of class time with the help of blackboard and chalk. It is evident to 
see that the objective and method are improper for the raised requirements at present for the civil engineering employees.

Short of Qualified Teachers.Shortness of qualified teachers is one of the problems for the course. As we have mentioned, this course is at present either taught by teachers of elementary English courses, who are lack of professional knowledge of civil engineering, or taught by teachers of civil engineering major courses, who have professional knowledge but are not good at English. So, it is necessary for this course to have qualified teachers who are both rich in professional knowledge and good at English, which maybe enhance the students' interest in this course, for the teachers could analyze and explain the teaching materials fluently and accurately in English, which the students are eager to be exposed to.

Students' Lack of Interest. Students have little interest in civil engineering English. There are many reasons. Firstly, the course for civil engineering English is generally taken as a specialized elective course, which the class-time is only half of the time of an elementary English course. Meanwhile, the course is commonly scheduled in the third or fourth year, which caused there is no natural transition between the elementary English courses and the course for civil engineering English. Secondly, students pay much attention to College English Test (Band 4 and Band 6), for most of the colleges and universities in China take the passing rate of the two tests as an important criterion for the evaluation for the quality of teaching and require the students must pass the two tests, or just Band 4. Instead, there is no such requirement for the students in civil engineering English, which made the students lack of interest and initiative in the course. Thirdly, most of them think it is unnecessary in their future, for they will stay in China and have little chance to use English. And those who choose this course are either curious about the content, or about to take the entrance exams for postgraduate schools. These students, then, would lose interest soon after they get in touch with civil engineering English, or put much emphasis on learning grammar without notice of technical terms and practice of other English abilities.

\section{Teaching Reform of Civil Engineering English Course}

Civil engineering English, as a kind of ESP, is goal-oriented and then its teaching should be on the basis of need analysis, including analysis of target needs and learning needs. Professor Su classifies needs into two types. One is social needs, which refer to the political needs of the government and the needs of organizations, such as companies, schools and others. The other is personal needs which refer to a person's objective needs, such as his age, educational background, learning and working experiences, and subjective needs, such as his expectations, learning targets, learning arrangement, expected teaching ways and so on.. according to her study, the units of choosing and employing staff usually have a high expectation of English ability of working staff in translation, communicating, and writing, while the students hope to expand their knowledge in real estate, construction management and so on.

Concerning the needs of the units of choosing and employing staff and students, the paper is to propose the following teaching reform design from teaching materials, teaching objectives, teaching methods, the cultivation of teachers, and the motivation of students.

To Update the Teaching Materials.As mentioned above, teaching materials should be updated. But, since civil engineering is a practical and professional field, it is not an easy job to find a professional textbook, which contains all the needed things and is suitable for all majors in civil engineering. Then to edit textbooks according to the English levels and demands of students in their own subjects is necessary. Generally, there are three levels for the students to choose to start their learning, the primary, intermediate, and senior levels. For the primary level, the textbook should contain materials rich in technical terms but simple in sentence structure for the students to learn, for at this level, students have common English knowledge but lack professional one. Then for the intermediate level, the textbook should begin to add technical documents and files for the students to improve their reading and understanding for the professional literature. Then for the last level, the textbook should include the materials which reflect upon the latest development of this field, which can help the students get familiar with the outside world. Meanwhile, the materials for the 
three levels should be selected carefully in a broad range. The materials should not only be chosen from the original English books, , but also from the academic journals, magazines, instructions and so on, in the hope that the students could access to the latest information of civil engineering easily.

To Alter the Teaching Objective and Use Teaching Methods Rationally and Reasonably. The course should try to make sure that the students could have the chance to practice all the English abilities, such as reading, writing, speaking, listening, translation and so on. The students should be capable of reading the original English materials and finding out the main ideas and details, understand what he listens to, communicate and negotiate with others in simple things about civil engineering, and should write reports, plans or papers in English.

As the objectives change, the teaching methods should also be changed. In the past, the class was teacher-centered, but now all the teaching methods applied by the teachers should try to make the class student-centered so that the students have enough time to improve their English abilities. Students are the principal part of teaching. It is very important for the students to take the initiative in class. Teachers could ask the students to work in groups to finish tasks. The tasks should be closely related to their major, such as the construction of a bridge, the measurement of a road, the negotiation with the companies abroad about a stadium, the designation of a construction project, and so on. By these tasks, the students work with group members in English, then they gradually remember the technical terms unconsciously and have a sense of achievement by solving all the problems by themselves in English. They would be afraid that they can not do things in English. Instead, with the guidance of teachers, students do things by themselves in English confidently.

To Cultivate Qualified Teachers.To have qualified teachers is an essential part for the teaching reform of the course. The above has referred to the reason for the necessity of qualified teachers. We could cultivate teachers from two channels. The first is that colleges and universities could provide all the chances for the Chinese professional teachers to improve their English ability, such as teaching seminars, abroad studying, lectures and conferences given by foreign experts, annual requirements of translation and writing in English and so on. Another is that colleges and universities could invite foreign experts to be the teachers, to which the main problem is the cost.

To Motivate Students.Interest is the best teacher for a person to learn something. Then how to motivate students and arouse their interest is very essential. First, the course should be taken seriously, which would be evaluated with other major courses and recorded in their academic paper. Second, the colleges and universities should shift their emphasis from College English Test to their professional English, taking their subjects into consideration. Third, teachers should tell the importance and raised requirements of civil engineering English so as to warn students and guide them to concentrate on the learning of civil engineering English, not for the test but for their better future. Fourth, teachers should flexibly use all kinds of teaching methods, teaching materials and other teaching tools, such as computer, multimedia, etc. to enliven the class and enlighten the students. For instance, when teachers ask students to translate the long sentences, they can provide some English video clips of their major, such as Three Gorges Dam, Eiffel Tower. By this, students will find learning is not boring and useful for expanding their professional knowledge. Last, if possible, teachers should provide chances for the students to practice and test their capability outside campus, which, help students remember and consolidate what they have learnt, and make students get in touch with the outside world and alert them to the importance of learning.

\section{Conclusion}

To design a plan for the teaching reform of civil engineering English course is very simple in a sense, but the key is how to carry out the plan. It does not only need the effort of teachers, but also demand the participation of students, colleges and the whole society. Without the effort of any of them, the plan would just be shelved and forgotten. And with the intense cooperation and interaction with the foreign companies and organization, civil engineering English play an important role. By this paper, the writer hope more and more people will reflect upon the problems of the course and do the research on it. 


\section{References}

[1]Dong Jianmiao. The Teaching Features and Reform of Civil Engineering English. Journal of Guangxi Institute of Technology, 2005 (6): 10-11.

[2]Gou Hanmei. Discussion of Specialized English Teaching for Architecture Engineering in Higher Vocational Colleges. Journal of Chongqing College of Electronic Engineering, 2012 (2): 130-132.

[3]Huang Shuyun. Jiyu Gongzuo Guocheng Zhong de Tumu Gongcheng Zhuanye Yingyu Kecheng Biaozhun Yanju. Theory and Practice of Contemporary Education, 2011 (9): 83-85.

[4]Liu Guilan \& Shao Juanping. An Inquiry into the Quality Education to the Cultivation of Engineering English Translation Talents. Journal of Hubei TV University, 2011 (1): 106-107.

[5]Liu Wenjun. Jiyu ESP Lilun de Gaozhi Tumu Gongcheng Yingyu Jiaoxue Gaige Tantao. 2011 (5): 161-162. 